
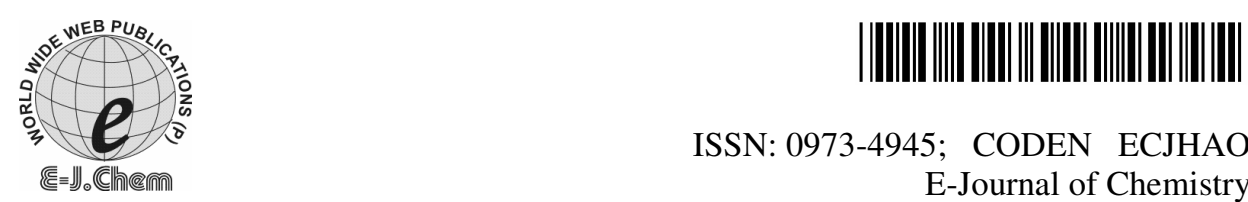

ISSN: 0973-4945; CODEN ECJHAO

http://www.e-journals.net

E-Journal of Chemistry 2009, 6(3), 938-942

\title{
Inhibition of Mineralization of Urinary Stone Forming Minerals by Medicinal Plants
}

\author{
N. A. MOHAMED FAROOK ${ }^{*}$, S. RAJESH and M. JAMUNA \\ *P. G. Department of Chemistry, Department of Biochemistry, \\ Khadir Mohideen College, Adirampattinam-614701, India.
}

Received 1 November 2008; Accepted 2 January 2009

\begin{abstract}
The inhibition of mineralization of urinary stone forming minerals by medicinal plants i.e. Achyranthes aspera Linn, Passiflora leschenaultii DC, Solena amplexicaulis (Lam.) Gandhi, Scoparia dulcis Linn and Aerva lanata (Linn.) been investigated. The inhibition efficiency was studied. Increased intake of fruits juice and seed extract of our plants would be helpful in urinary stone prophylaxis.
\end{abstract}

Keywords: Urinay Stone, Urolithiasis, Medicinal plant, Inhibition

\section{Introduction}

A number of people suffer from problems due to urinary stones (calculi). Areas of high incidence of urinary calculi include the British Isles, Scandinavian countries, Northern Australia, Central Europe, Northern India, Pakistan and Mediterranean countries. Saurashtra region, Gujarat has higher prevalence of urinary stones. According to an estimate, every year 600,000 Americans suffer from urinary stones. In India, $12 \%$ of the population is expected to have urinary stones, out of which $50 \%$ may end up with loss of kidneys or renal damage. Also, nearly $15 \%$ of the population of northern India suffers from kidney stones. Fewer occurrences of urinary calculi are found in southern India, which may be due to regular dietary intake of tamarind.

Kidney stones are the commonest universal complaints ${ }^{1}$. Kidney stones modify the victim's behavior with great fear of intense pain and threaten with failure of the kidneys. In modern medicine no satisfactory effective therapy is still available to dissolve or to prevent acetozolamide are available against uric acid and cystine stone, although several drugs / therapies such as thiazides, cellulose phosphate, magnesium oxide and pyridoxine etc. have been tried. On the other hand the traditional system of Indian medicine "Ayurveda" recommends several medicinal plants ${ }^{2-8}$ for the treatment of Urolithiasis. Urolithiasis disease exists in 'endemic' proportions in some parts of our country. Urinary stones contain both crystalloid and colloid components. The crystalloid components are mainly calcium oxalate, calcium phosphate, calcium carbonate, magnesium-ammonium phosphate, uric acid and cysteine. In the present work we have estimated the inhibition efficiency of medicinal plants, 
i.e. Achyranthes aspera Linn (P1), Passiflora leschenaultii DC (P2), Solena amplexicaulis (Lam.) Gandhi (P3), Scoparia dulcis Linn (P4) and Aerva lanata (Linn.) (P5) on the mineralization of calcium oxalate, calcium carbonate and calcium phosphate.

\section{Experimental}

\section{Materials and Methods}

All the chemicals used were of AR grade. Crystalloid forming solutions, viz., solution of calcium acetate, disodium oxalate, sodium carbonate and trisodium phosphate, were prepared in distilled water.

Plant material for the present work was collected locally and was identified botanically. Leaves were carefully removed from the plants and allowed to dry in the sun light. The dried leaves were made into a powder and extracted with 95\% ethanol. The extract was concentrated. The residue was suspended in water. Seed extract was prepared by the following procedure.

Juice of the fruits was extracted with help of an ordinary fruit juicer. The thick juice obtained, were passed through a mesh and then suction filtered through ordinary filter paper. All the juice was used diluted to a known concentration.

Four experimental models namely 'simultaneous flow static model' (S.S.M.), 'simultaneous flow dynamic model' (S.D.M.), 'reservoir static model' (R.S.M.) and 'reservoir dynamic model' (R.D.M.) were designed ${ }^{11}$. The medicinal plant was collected from hills area and botanically identified ${ }^{9}$. The experiments were carried out in the laboratory. Simultaneous blank experiments were also carried out for evaluating the inhibition efficiency of inhibitor. All the experiments were conducted at room temperature. Percentage efficiency of inhibitor was calculated ${ }^{10}$.

\section{Results and Discussion}

Inhibition efficiencies of leaves, seeds and fruits of the medicinal plants (P1-P5) have been investigated in different models. The results are recorded in Table 1. Study of the tables and charts (Figures 1-5) suggests that the fruit juice and seed extract of the medicinal plants is moderate to good inhibitor of calcium oxalate, calcium carbonate and calcium phosphate mineralization. Sequestering of this insoluble calcium salts by the fruit juice might be due to effective single or mixed ligand chelation by the hydroxyl acids present in them. The hydroxyl acids are expected to form metal ion complexes with calcium. The presence of hydroxyl acids in urine may decrease the amount of ionized calcium available for calcium oxalate precipitate. Relatively poor inhibition of mineralization of calcium oxalate, calcium phosphate and calcium carbonate precipitation by leaves extracts might be due to a higher $\mathrm{pK}$ value of carbonic acid leading to replacement and precipitation of calcium salts of inhibitors rather than soluble mixed chelation ${ }^{11}$. Calcium oxalate is a stubborn constituent of urinary calculi being highly insoluble. It has very poor solubility in the leaves extract as such; however, if the fruit juices are present in the milieu before the formation of calcium oxalate, they may prevent the precipitation of the latter by exerting the specificity of their inhibitor towards calcium ions.

The average inhibition efficiency for all the models is present in the Table 2. The calcium oxalate mineralization is most effective in all the plants. The calcium phosphate mineralization is moderate in all the plants. The effect of inhibition efficiency of leaves extract is very poor in all the cases. A comparative study of different models indicates that the reservoir dynamic model is the most effective one in the inhibition of calcium oxalate 
mineralization. This might be due to mass effect. An ab-initio presence of large concentration of juice (in the reservoir) leads to minimize the free $\mathrm{Ca}^{2}+$ ions for precipitation as insoluble salts. Most of the fruits contain hydroxyl polybasic acids. Our present study suggests that the increased intake of fruits juice and seed extract of our plants would be helpful in urinary stone prophylaxis.

Table 1. Inhibition of (1) Calcium oxalate (2) Calcium phosphate and (3) Calcium carbonate Mineralization by medicinal plants.

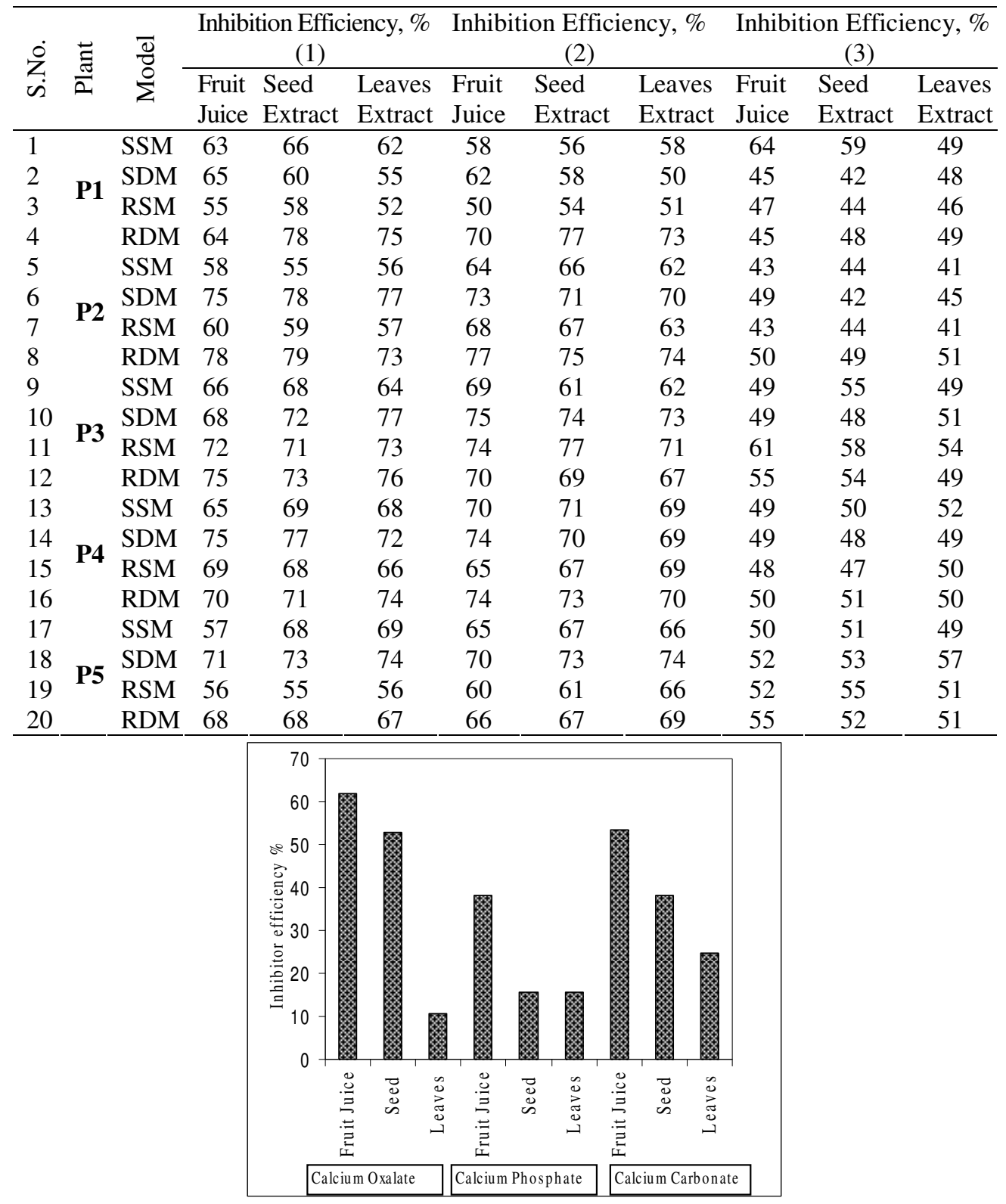

Figure 1. Inhibition Efficiency of Achyranthes aspera Linn (P1). 


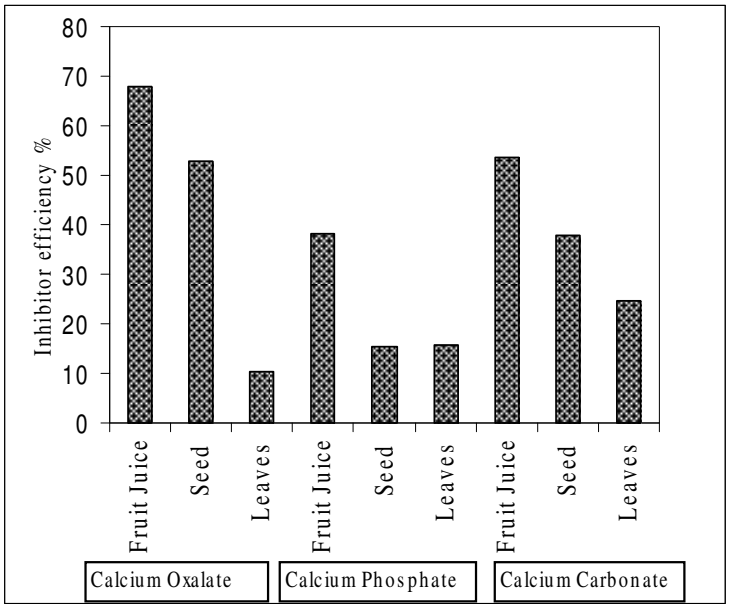

Figure 2. Inhibition Efficiency of Passiflora leschenaultii DC (P2).

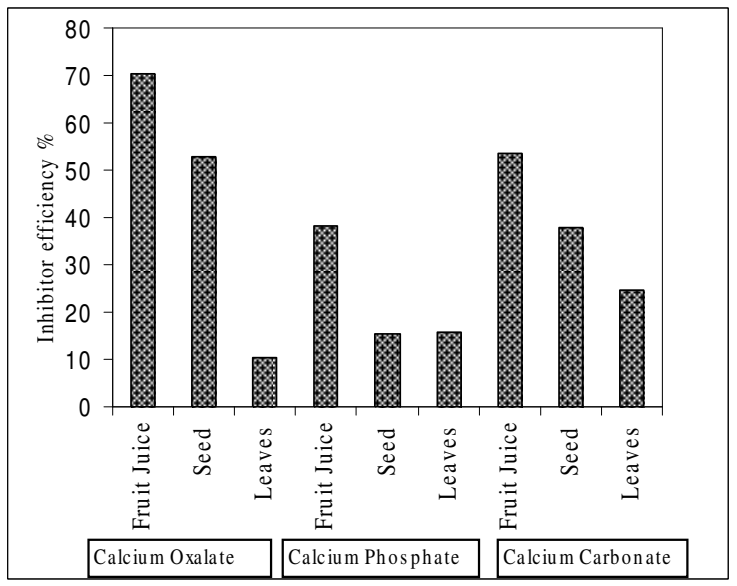

Figure 3. Inhibition Efficiency of Solena amplexicaulis (Lam.) Gandhi (P3).

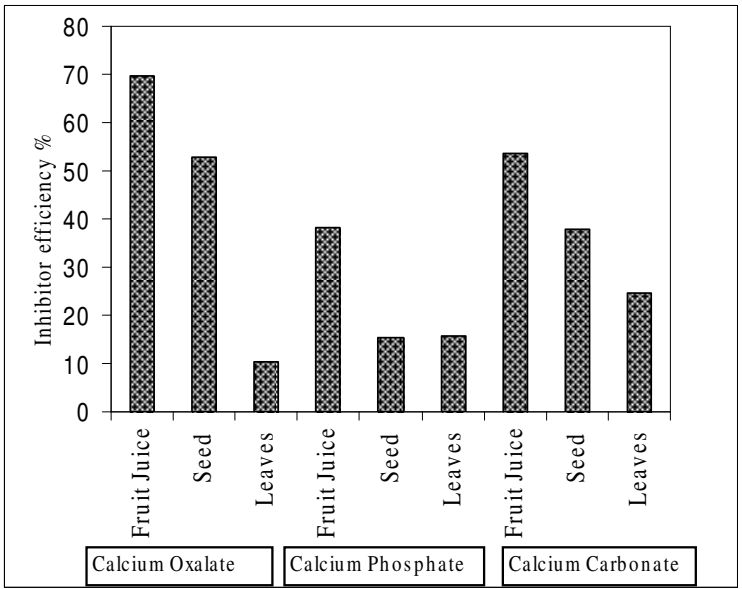

Figure 4. Inhibition Efficiency of Scoparia dulcis Linn (P4). 


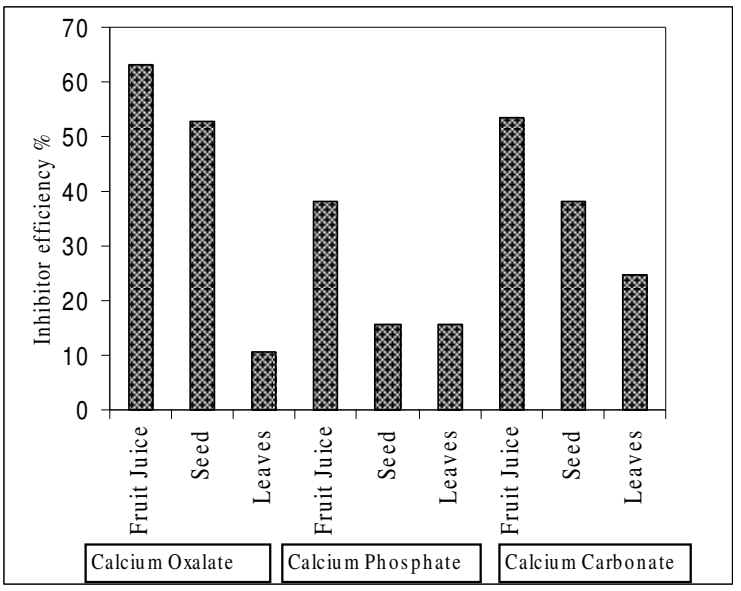

Figure 5. Inhibition Efficiency of Aerva lanata (Linn.) (P5).

Table 2.Average inhibition efficiency of all models.

\begin{tabular}{clrrrrr}
\hline \multirow{2}{*}{ Stone } & \multirow{2}{*}{ Plant parts } & \multicolumn{5}{c}{ Inhibition efficiency, \% } \\
\cline { 3 - 7 } & & P1 & P2 & P3 & P4 & P5 \\
\hline \multirow{2}{*}{ Calcium } & Fruit Juice & 61.75 & 67.75 & 70.25 & 69.75 & 63 \\
oxalate & Seed & 52.75 & 52.75 & 52.75 & 52.75 & 52.75 \\
& Leaves & 10.5 & 10.5 & 10.5 & 10.5 & 10.5 \\
\multirow{2}{*}{ Calcium } & Fruit Juice & 38.25 & 38.25 & 38.25 & 38.25 & 38.25 \\
phosphate & Seed & 15.5 & 15.5 & 15.5 & 15.5 & 15.5 \\
& Leaves & 15.75 & 15.75 & 15.75 & 15.75 & 15.75 \\
& Fruit Juice & 53.5 & 53.5 & 53.5 & 53.5 & 53.5 \\
\multirow{2}{*}{ Calcium } & Seed & 38 & 38 & 38 & 38 & 38 \\
carbonate & Leaves & 24.75 & 24.75 & 24.75 & 24.75 & 24.75 \\
& & & & & & \\
\hline
\end{tabular}

\section{Acknowledgement}

The main author is thankful to UGC, SERO, Hyderabad, for their financial assistance to complete this project work successfully.

\section{References}

1. Joseph K C, Bharat, Parekh, B and Joshi M J, Current Science, 2005, 88 (25),1232.

2. $\quad$ Prasad et.al. Int J Pharm, 1997, 35, 278-83.

3. Kessler et.al. Eur J Clin Nutr, 2002, 56, 1020-30.

4. Vimal S Joshi et.al., Indian J Pure Appl Phys., 2003, 41, 183-192.

5. Solis R V and Gutierrez, J Ethanopharmacology, 2002, 83, 145-47.

6. Massey et.al., J Agr Food Chem., 2001, 49, 4262-66.

7. $\quad$ P.P Singh et.al, Indian J Exp Biol., 1987, 25, 863-65.

8. Ahamed J, Khalid N, and Jabeen E, Pak J Sci Ind Res., 1987, 30, 205-207.

9. http://www.himalayahealthcare.com

10. Rao T V K and Mytreye Dass, Asian J Chem., 2000, 12, 719.

11. Mohamed Farook N A, Seyed Dameem and Sathya, E J Chem., 2004, 1,137. 


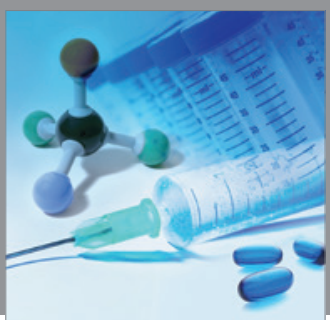

International Journal of

Medicinal Chemistry

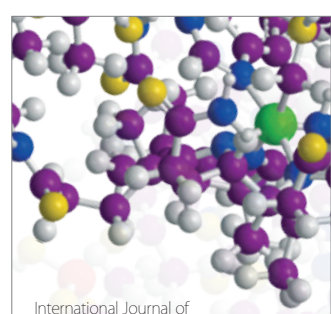

Carbohydrate Chemistry

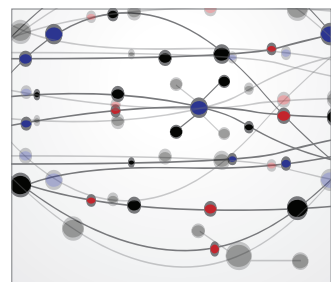

The Scientific World Journal
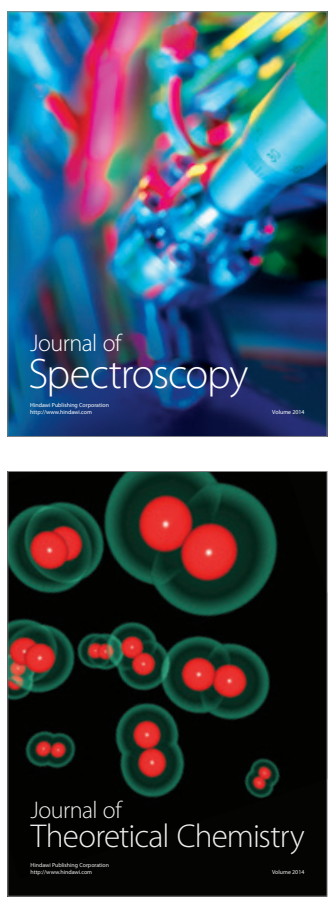
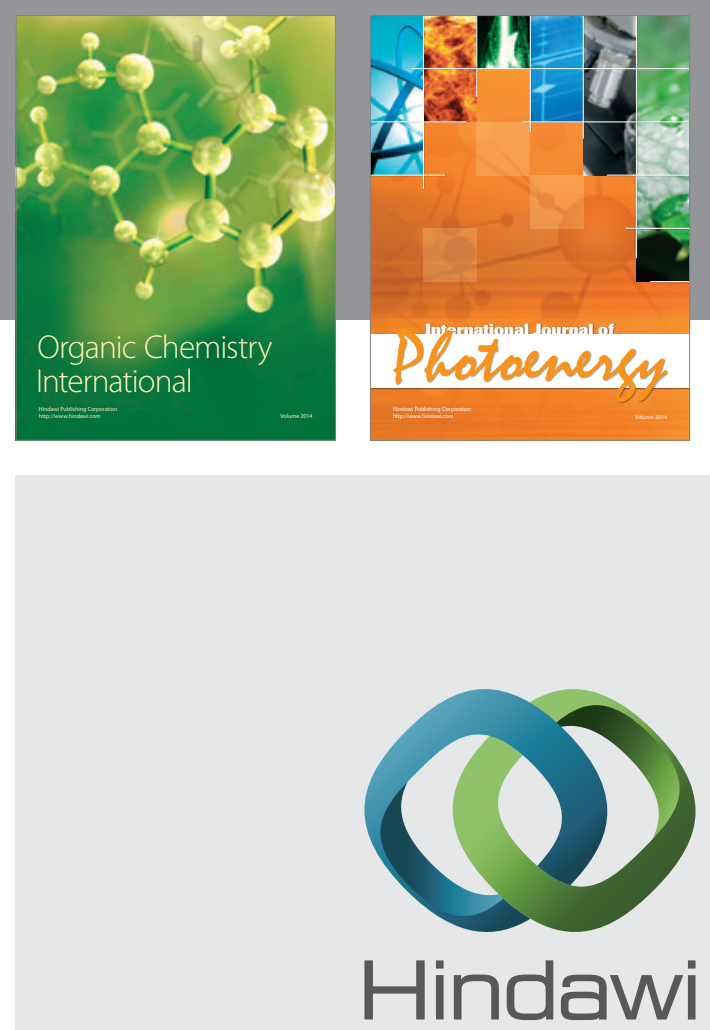

Submit your manuscripts at

http://www.hindawi.com
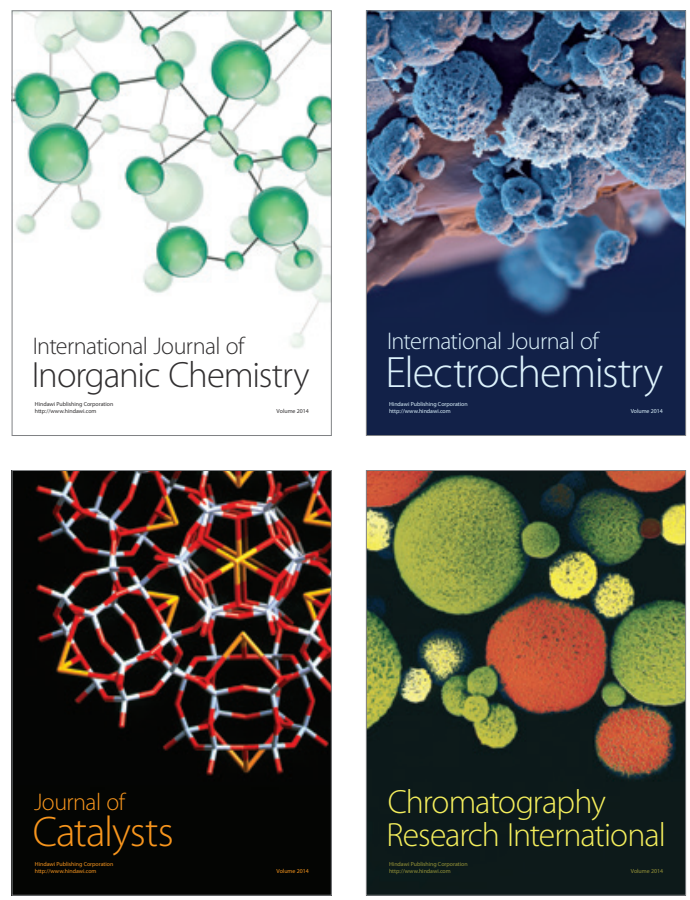
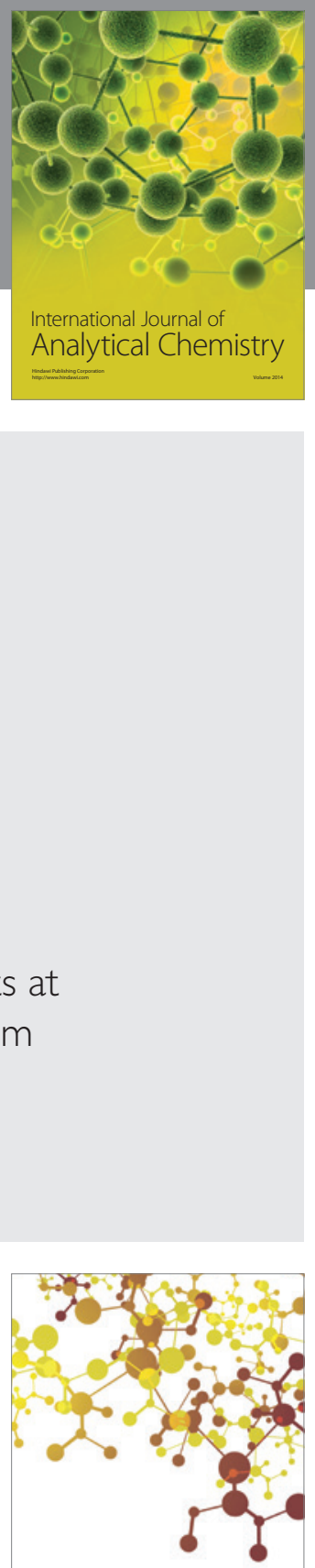

Journal of

Applied Chemistry
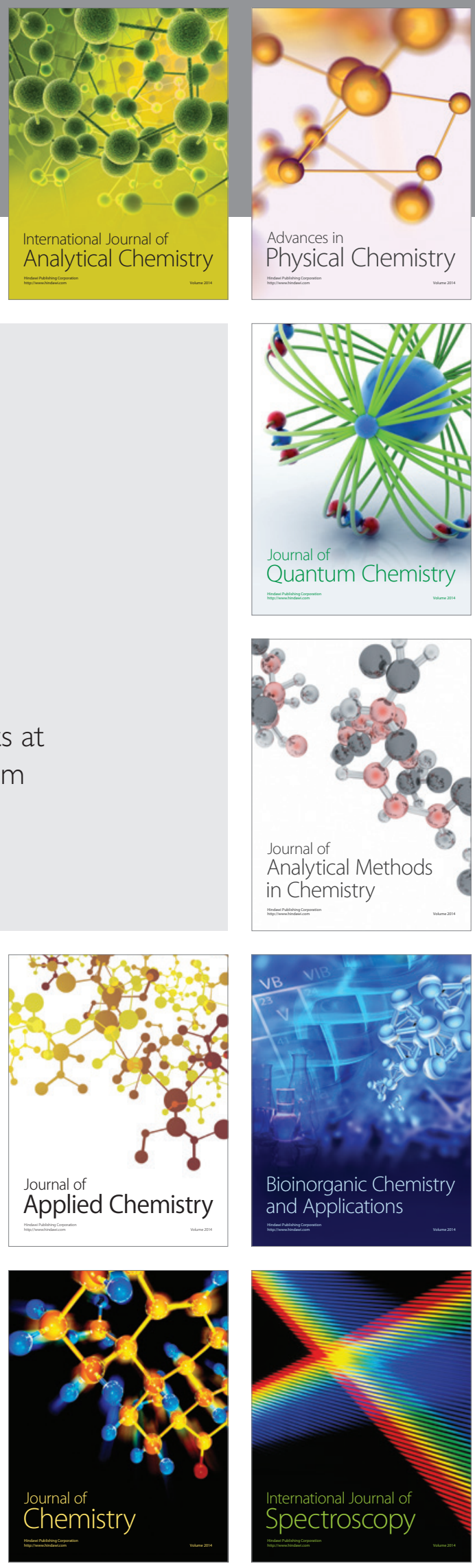